\title{
Geographies of the ageing-migration nexus: An introduction
}

\author{
Dora Sampaio $^{1,2}$ (D) | Russell King ${ }^{1}$ (D) | Katie Walsh ${ }^{1}$ (D)
}

${ }^{1}$ Department of Geography, University of Sussex, Brighton, UK

${ }^{2}$ Centre for Geographical Studies, University of Lisbon, Lisbon, Portugal

\section{Correspondence}

Dora Sampaio

Email: d.sampaio@sussex.ac.uk
This special section builds on previous scholarship on geographies of ageing, and on relational and transnational approaches to age and migration, to assert the significance of the ageing-migration nexus in human geography. Our primary goal is to examine the intricate relationships between ageing, migration, space and place. By bringing empirical research on ageing and migration into dialogue with existing conceptual work within Geography, we also aim to critically contribute to current debates in both areas. The contributors explore a wide range of migration processes and experiences through an intersectional lens, and demonstrate the importance of a diverse set of epistemological and methodological approaches to explore the spatialities of the ageing-migration nexus. Key dimensions examined include, but are not limited to, the spaces and places of ageing and migration, the multi-scalar nature of the geographies of the ageing-migration nexus, their (im)mobilities, fluid boundaries, and emotional geographies.

\section{K E Y W O R D S}

ageing, geography, intersectionality, migration, place, space

The intersections between ageing and migration have profound geographic resonance. In this special section, we seek to illuminate emplaced meanings of age and ageing, and related (im)mobilities, produced over space and time, demonstrating that place is more than a mere "container" of older people (Andrews et al., 2007; Pain et al., 2000). Existing research allows us to map out these crossings in three substantive areas of concern, relevant for both academic work and policymaking: the increasing diversity of ageing migrants in all parts of the globe, both internally and across borders, and related social, cultural, economic, health and welfare-specific challenges; the multiplicity of ageing landscapes and the nuanced nature of migrants' home-unmaking practices, social and intimate relationships in later life, ageing cultures and ageing care; and the interstitial dimensions and individual subjectivities that mould prescribed experiences of age and ageing, and their varied entitlements across the world.

We argue that it is by looking at the spaces and places of our everyday lives, both relationally and transnationally, that the ageing experience as an ongoing, (im)mobile, social project can be further understood. Pertinent questions that this special section addresses include the following. What are the implications of (trans)national migration for ageing as both an embodied and emplaced experience? How does geographical mobility impact migrants' wellbeing in later life? Do older migrants' ideas about age and ageing shift across space and time? How is ageing care articulated across borders and what are the consequent challenges for migrants and non-migrants? In what ways are later-life identities and home-making experiences shaped at different social and spatial scales? How is privilege, accumulated over the life course, enacted in new geographical contexts? And, how are migrants' social and intimate relationships shaped by their (im)mobilities and emplacement?

Geographical research has worked towards developing "geographies of ageing" as a distinct research arena of Human Geography. While the origins of this research theme can be traced to early statements by Rowles (1986), Warnes (1990) 
and Harper and Laws (1995), recent studies have drawn attention to a variety of geographical and spatial concerns. These include the intertwining of social and cultural, and biological and physiological, dimensions of ageing and later life; the challenge of incorporating time and spatiotemporality in discussions about ageing (Schwanen et al., 2012); and the potential for relational and non-representational approaches to age and ageing within Geography (Hopkins \& Pain, 2007; Skinner et al., 2015). In particular, the development of relational geographies of age has provided a robust platform for exploring the nexus between different social-chronological groups, shedding light on core intergenerational, intersectional and lifecourse issues. Simultaneously, geographers, through their methodological and epistemological pluralism and multiscale approaches, have been able to provide a spatially sensitive analysis of the growing diversity of mobilities in a globalised, yet fundamentally divided, world (King, 2012). While these two strands of geographical engagement - on age and ageing and on migration - have been prolific on their own, their crossings have remained underdeveloped.

On the whole, the study of the complex intersections of ageing and migration has established itself as an important and timely agenda across the social sciences. This has taken place chiefly through a flurry of edited volumes and special issues (e.g., Baldassar et al., 2007; Ciobanu \& Hunter, 2017; Ciobanu et al., 2017; Horn \& Schweppe, 2015; Horn et al., 2013; Karl \& Torres, 2016; Lawrence \& Torres, 2015; Näre et al., 2017; Torres \& Lawrence, 2012; Walsh \& Näre, 2016; Warnes \& Williams, 2006; Zubair \& Norris, 2015). Fruitful discussions have developed on the diversity of older migrants (Warnes et al., 2004), transnational ageing (Horn \& Schweppe, 2017), identities and everyday practices in older age (Näre et al., 2017), elderly care (Baldassar et al., 2007), ageing in ethnic minority or transcultural contexts (Zubair \& Norris, 2015), ageing and the new media (Baldassar et al., 2017), and policy implications of ageing as a migrant (Ciobanu et al., 2017). Notwithstanding their thematic richness, these analyses have, for the most part, failed to fully engage with the spatial dimensions of the ageing-migration nexus. This is the lacuna we seek to fill with this collection.

This special section asserts the importance of carving a space for the ageing-migration nexus in Human Geography as the appropriate arena to develop relationships between ageing, migration, space and place. It offers novel insights into the wider debates on ageing and migration by foregrounding geographical analyses of the ageing-migration nexus. In doing so, we respond to Cutchin's avowal that "the study of the geographical dimensions of ageing has yet to achieve its full potential" (2009, p. 440). Providing innovative extensions to existing analyses of migration, we build on the conceptual strength of work on geographies of ageing (Harper \& Laws, 1995) and a relational approach to age (Hopkins \& Pain, 2007) that has helped to transform understandings of older age in Human Geography, Gerontology and beyond (Andrews \& Phillips, 2005; Hardill, 2009; Schwanen et al., 2012; Skinner et al., 2015, 2018).

The papers included in this special section offer forward-looking approaches to the study of the ageing-migration nexus through a geographical lens, revealing ageing as a geographically contingent, spatially produced and embodied social process. They explore a wide diversity of migration processes and experiences through an intersectional approach to migrant subjectivities that is sensitive to the inequalities of ageing. Attention is drawn to migrants who are both wealthy and underprivileged; "young old" and "old old"; male and female; active and sedentary; healthy and frail; moving alone and as part of a couple; and originating from/located in both the Global North and Global South. The papers exemplify a variety of epistemological approaches which demonstrate the importance of a rich and diverse methodological toolkit for exploring geographies of the ageing-migration nexus. Papers are based on quantitative surveys and longitudinal data, qualitative indepth interviewing and biographical life-narratives, ethnography, comparative analysis, and visual methods.

The special section begins with intersectional discussions of ageing, in which age, gender, class and ethnicity are considered through a transnational lens. First, Oliver et al.'s (2018) study of "choice homophily" in later life provides an ethnographic account of two distinct geographical settings - international retirement migration to Spain and older people's centres in South London - critically exploring the configuration of spaces of ageing in relation to similarity and difference. Second, Lulle's (2018) paper conceptualises relational ageing in spatial and comparative terms. It examines transnational ageing care through a time-space approach that unfolds the life stories and intra-gender and cross-generational care practices of Latvian women who migrated and those who stayed put.

A focus on the lives of older lifestyle migrants is provided in the two papers that follow. Sampaio (2018) explores the inner geographies of ageing lifestyle migrants in the Azores islands, stressing the role of individuality and a "shift to the self" as an opportunity for self-actualisation in later life. She demonstrates that ageing as a single person does not always lead to vulnerability, but can be also empowering. Hayes' (2018) paper exposes the complexity behind self-perceptions of privilege, looking at how relative advantage and "white alterity" are negotiated by North Americans in Cuenca, Ecuador. The paper reveals the conflicted nature of migrants' relayed concern with the local community while, simultaneously, taking advantage of structural global inequalities.

Walsh (2018) and Cela and Bettin's (2018) papers consider the phenomenon of return migration in older age, each using a different methodological lens. Walsh deploys "critical geographies of home" and uses in-depth repeat interviewing with older 
Britons to explore their home-making practices back in Britain; Cela and Bettin's study draws on German Socio-Economic Panel data to provide a detailed quantitative analysis of subjective and objective wellbeing-related factors implicated in the decision to return to the country of origin in older age. Wellbeing in later life is also at the core of Finney and Marshall's (2018) paper, which, based on data from the English Longitudinal Study of Ageing, discusses the potentially advantageous effects of residential mobility in later life, and how this can help to explain ageing inequalities at various scales.

Taken together, these papers draw attention to five dimensions of the geographies of the ageing-migration nexus that merit further analysis: first, the spaces and places of ageing and migration, in their emplaced and embodied socio-economic and cultural diversity and homogeneity, and potential for re-configurations over time; second, their multi-scalar nature, including (trans)national, community and home spaces, ranging from the well-researched migration flows in the Global North to the emerging ageing mobilities in the Global South; third, their (im)mobilities, encompassing both migrants and non-migrants and the promises, but also the constraints, of geographical mobility later in life; fourth, their boundaries, which become increasingly difficult to disentangle with different types of migration - be they economically, family or lifestyle oriented - overlapping and feeding into each other; and fifth, their emotional geographies, which highlight ever more reflexive cultures of age and ageing.

Finally, this collection of papers suggests promising avenues for future research. These include, but are not limited to, the following. We suggest that research could be more inclusive of a diversity of ageing migrants and mobility motives, thereby recognising the limitations of current migration categorisations and emphasising the importance of life-course transitions. Studies are required that are more attentive to the relations between migrants and non-migrants and the complex ways in which they interact, for instance in terms of ageing care as shown in Lulle's paper, but also regarding transnational cultures of ageing, place attachment, and social and generational interactions and expectations. Research espousing intersectional approaches that observe the relations between life stage (e.g., separation, illness, bereavement etc.), gender, class, sexuality, race, ethnicity and inequality, as demonstrated by all papers in this collection, is also important to develop more widely. Likewise, studies that explore determinants of health impairment and wellbeing in later life and foreground collaborations between different strands of Geography, such as geographies of health, ageing, and economic, social and cultural geographies. Research is needed that incorporates a de-colonial lens and goes beyond "the West," such as that of Hayes (this collection), which inspires further work focusing on the diversity of ageing-migration crossings in understudied geographical contexts. And, lastly, in their methodological plurality, the set of papers in this special section invites further methodological imagination in the study of the ageing-migration nexus, for example through the inclusion of more nonrepresentational, historical, media-focused, and cartographically and photographically documented research.

\section{ACKNOWLEDGEMENTS}

The majority of the papers in this special section were originally presented at the RGS-IBG Annual Conference in 2016. We are very grateful for the enthusiasm and energy that the authors, the anonymous reviewers, and the Editor and the managing Editor of Area have put into this special section.

\section{OR CID}

Dora Sampaio (iD http://orcid.org/0000-0002-0036-9989

Russell King (iD http://orcid.org/0000-0001-6662-3305

Katie Walsh (D) http://orcid.org/0000-0003-4136-3847

\section{REFERENCES}

Andrews, G. J., Cutchin, M., McCracken, K., Phillips, D. R., \& Wiles, J. (2007). Geographical gerontology: The constitution of a discipline. Social Science \& Medicine, 65, 151-168. https://doi.org/10.1016/j.socscimed.2007.02.047

Andrews, G. J., \& Phillips, D. (Eds.) (2005). Ageing and place. Perspectives, policy, practice. Oxon, UK: Routledge.

Baldassar, L., Baldock, C. V., \& Wilding, R. (2007). Families caring across borders: Migration, ageing, and transnational caregiving. New York, NY: Palgrave Macmillan. https://doi.org/10.1057/9780230626263

Baldassar, L., Wilding, R., Boccagni, P., \& Merla, L. (2017). Aging in place in a mobile world: New media and older people's support networks. Transnational Social Review, 7, 2-9. https://doi.org/10.1080/21931674.2016.1277864

Cela, E., \& Bettin, G. (2018). Returning to the country of origin in later life: Longitudinal evidence from the German Socio-Economic Panel. Area, 50, 483-491. https://doi.org/10.1111/area.12438 
Ciobanu, R. O., Fokkema, T., \& Nedelcu, M. (2017). Ageing as a migrant: Vulnerabilities, agency and policy implications. Journal of Ethnic and Migration Studies, 43, 164-181. https://doi.org/10.1080/1369183X.2016.1238903

Ciobanu, R. O., \& Hunter, A. (2017). Older migrants: (Im)mobilities of ageing. Population, Space and Place, 23, 1-10. https://doi.org/10.1002/ psp. 2075

Cutchin, M. P. (2009). Geographical gerontology: New contributions and spaces for development. The Gerontologist, 49, 440-445. https://doi. org/10.1093/geront/gnp095

Finney, N., \& Marshall, A. (2018). Is migration in later life good for wellbeing? A longitudinal study of ageing and selectivity of internal migration. Area, 50, 492-500. https://doi.org/10.1111/area.12428

Hardill, I. (2009). Introduction: Geographies of aging. The Professional Geographer, 61, 1-3. https://doi.org/10.1080/00330120802577509

Harper, S., \& Laws, G. (1995). Rethinking the geography of ageing. Progress in Human Geography, 19, 199-221. https://doi.org/10.1177/ 030913259501900203

Hayes, M. (2018). The gringos of Cuenca: How retirement migrants perceive their impact on lower income communities. Area, 50, $483-491$. https://doi.org/10.1111/area.12460

Hopkins, P., \& Pain, R. (2007). Geographies of age: Thinking relationally. Area, 39, 287-294. https://doi.org/10.1111/j.1475-4762.2007.00750.x

Horn, V., \& Schweppe, C. (Eds.) (2015). Transnational aging - Current insights and future challenges. New York, NY: Routledge.

Horn, V., \& Schweppe, C. (2017). Transnational aging: Toward a transnational perspective in old age research. European Journal of Ageing, 14, 335-339. https://doi.org/10.1007/s10433-017-0446-Z

Horn, V., Schweppe, C., \& Seong-Gee, U. (2013). Transnational aging-A young field of research. Transnational Social Review, 3, 7-10. https://doi.org/10.1080/21931674.2013.10820744

Karl, U., \& Torres, S. (Eds.) (2016). Ageing in contexts of migration. Oxon, UK: Routledge.

King, R. (2012). Geography and migration studies: Retrospect and prospect. Population, Space and Place, 18, 134-153. https://doi.org/10.1002/ psp. 685

Lawrence, S., \& Torres, S. (Eds.) (2015). Older people and migration: Challenges for social work. Oxon, UK: Routledge.

Lulle, A. (2018). Relational ageing: On intra-gender and generational dynamism amongst ageing Latvian women. Area, 50, 452-458. https://doi. org/10.1111/area.12427

Näre, L., Walsh, K., \& Baldassar, L. (2017). Ageing in transnational contexts: Transforming everyday practices and identities in later life. Identities, 24, 515-523. https://doi.org/10.1080/1070289X.2017.1346986

Oliver, C., Blythe, M., \& Roe, J. (2018). Negotiating sameness and difference in geographies of older age. Area, 50, 444-451. https://doi.org/10. 1111/area. 12429

Pain, R., Mowl, G., \& Talbot, C. (2000). Difference and the negotiation of 'old age'. Environment and Planning D: Society and Space, 18, 377393. https://doi.org/10.1068/d31j

Rowles, G. D. (1986). The geography of ageing and the aged: Toward an integrated perspective. Progress in Human Geography, 10, 511-539. https://doi.org/10.1177/030913258601000403

Sampaio, D. (2018). A place to grow older... alone? Living and ageing as a single older lifestyle migrant in the Azores. Area, 50, $459-466$. https://doi.org/10.1111/area.12414

Schwanen, T., Hardill, I., \& Lucas, S. (2012). Spatialities of ageing: The co-construction and co-evolution of old age and space. Geoforum, 43, 1291-1295. https://doi.org/10.1016/j.geoforum.2012.07.002

Skinner, M. W., Andrews, G. J., \& Cutchin, M. P. (Eds.) (2018). Geographical gerontology. Perspectives, concepts, approaches. Abingdon, UK: Routledge.

Skinner, M. W., Cloutier, D., \& Andrews, G. J. (2015). Geographies of ageing: Progress and possibilities after two decades of change. Progress in Human Geography, 39, 776-799. https://doi.org/10.1177/0309132514558444

Torres, S., \& Lawrence, S. (2012). An introduction to 'the age of migration' and its consequences for the field of gerontological social work. European Journal of Social Work, 15, 1-7. https://doi.org/10.1080/13691457.2012.661562

Walsh, K. (2018). Materialities and imaginaries of home: Geographies of British returnees in later life. Area, 50, 476-482. https://doi.org/10. 1111/area.12453

Walsh, K., \& Näre, L. (Eds.) (2016). Transnational migration and home in older age. New York, NY: Routledge.

Warnes, A. M. (1990). Geographical questions in gerontology: Needed directions for research. Progress in Human Geography, 14, $24-56$. https://doi.org/10.1177/030913259001400103

Warnes, A. M., Friedrich, K., Kellaher, L., \& Torres, S. (2004). The diversity and welfare of older migrants in Europe. Ageing \& Society, 24, 307-326. https://doi.org/10.1017/S0144686X04002296

Warnes, A. M., \& Williams, A. (2006). Older migrants in Europe: A new focus for migration studies. Journal of Ethnic and Migration Studies, 32, 1257-1281. https://doi.org/10.1080/13691830600927617

Zubair, M., \& Norris, M. (2015). Perspectives on ageing, later life and ethnicity: Ageing research in ethnic minority contexts. Ageing \& Society, 35, 897-916. https://doi.org/10.1017/S0144686X14001536

How to cite this article: Sampaio D, King R, Walsh K. Geographies of the ageing-migration nexus: An introduction. Area. 2018;50:440-443. https://doi.org/10.1111/area.12463 